\title{
UMA ANÁLISE SOBRE A ESTRATÉGIA COMERCIALDA ASSOCIAÇÃO DE AGRICULTORES DO CENTRO DE ABASTECIMENTO DE VOTORANTIM-SP
}

\author{
Daniel Bertoli GONÇALVES*
}

\author{
*Professor e Pesquisador do Programa de Pós-Graduação em Processos Tecnológicos e Ambientais - Mestrado \\ Profissional.danielbertoli@bol.com.br
}

Recebido em: 03/08/2015 - Aprovado em: 04/11/2015 - Disponibilizado em: 17/11/2015

\begin{abstract}
RESUMO
A comercialização dos produtos oriundos da agricultura familiar no Brasil tem passado por uma série de desafios nas últimas décadas, dadas as dificuldades enfrentadas principalmente pelos pequenos produtores com relação ao acesso aos melhores canais de comercialização. De forma a evitar essa situação e garantir maior segurança no mercado, uma considerável parcela da agricultura familiar tem investido em estratégias como o associativismo e o cooperativismo, com numerosos casos de sucesso pelo país. Todavia, enquanto grandes cooperativas conquistam espaço no mercado investindo na profissionalização e especialização de seus quadros técnicos e administrativos, grande parte das pequenas continua imersa em dificuldades financeiras e dependentes do apoio do poder público. Este estudo analisou o caso da Associação de Agricultores CEAVO - Centro de Abastecimento de Votorantim-SP, que em 2002, mesmo sem apoio público e profissionalização de seu quadro técnico e administrativo, investiu em uma estratégia arriscada de comercialização, ao criar um entreposto comercial próprio, para atender um público de feirantes, comerciantes e consumidores locais. Observou-se que, apesar de ter conquistado seu espaço no mercado junto a feirantes e comerciantes locais ao longo dos anos, a associação ainda se encontra em situação de fragilidade econômica, a qual pode ser atribuída em parte a falta de apoio institucional do poder público, e principalmente ao baixo grau de profissionalização de seu quadro técnico e administrativo, uma característica comum deste segmento que precisa ser contornada.
\end{abstract}

Palavras-Chave: agricultura familiar, associativismo, cooperativismo, comercialização, desenvolvimento regional.

\section{AN ANALYSIS ABOUT THE COMMERCIAL STRATEGY OF ASSOCIATION OF FARMERS OF VOTORANTIM-SP SUPPLY CENTER}

\begin{abstract}
The marketing of products from family farming in Brazil has experienced a number of challenges in recent decades, given the difficulties faced especially by small producers regarding access to the best marketing channels. In order to avoid this and ensure greater security in the market, a considerable portion of the family farm has invested in strategies such as associations and cooperatives, with numerous success stories across the country. However, while large cooperatives gain space in the market by investing in the professionalization and specialization of its technical and administrative staff, most small still immersed in financial difficulties and dependent on government support. This study examined the case of Farmers Association CEAVO - Supply Center Votorantim-SP, that in 2002, even without public support and professionalism of its technical and administrative staff, invested in a risky marketing strategy by creating its own trading post to meet an audience of merchants, traders and local consumers. It was observed that, despite having won its place in the market with the market traders and local merchants over the years, the association is still in a fragile economic situation, which can be attributed in part to lack of institutional support from the Government and especially to the low level of professionalism of its technical and administrative framework, a common feature of this segment that needs to be addressed.
\end{abstract}

Keywords: family farms, associations, cooperatives, marketing, regional development. 


\section{INTRODUÇÃO}

A pequena propriedade familiar e a organização comunitária, representaram os esteios da construção social do setor agrícola, onde, ao longo do tempo, emergiu o fenômeno do associativismo. De acordo com Cremonesee Schallenberger(1999), no final do século XIX e início do século XX a solidariedade entre os colonos era uma prática do cotidiano, cultuada, sobretudo, para fazer frente aos obstáculos naturais e às deficitárias condições de suprimento dos indivíduos e da coletividade. Ajudar o vizinho nas derrubadas, na colheita, nas edificações da propriedade e, na soma, na construção do espaço público eram institutos que caracterizam o perfil social dos sujeitos sociais oriundos das levas de migrantes europeus, que definiram o modelo hegemônico de assentamento de diversas regiões do país.

O Cooperativismo, segundo Becho (2002), é uma forma de ajuda mútua e cooperação. A cooperativa é uma associação de pessoas, que se unem de forma voluntária, com o objetivo de maximizar as aspirações e necessidades econômicas, sociais e culturais comuns, tendo como meio para este fim, uma entidade de propriedade conjunta chamada cooperativa, gerida de maneira democrática.

Essa forma de organização permite que um grupo de pessoas, com mesmo objetivo, através de cooperação mútua, com a união de trabalho e recursos, desenvolva melhorias sociais e econômicas com maiores e melhores resultados.

O surgimento do Cooperativismo data de 1844, em Manchester (Inglaterra). Segundo Coopeder (2007), o cooperativismo foi uma alternativa econômica, frente ao capitalismo ganancioso que os grupos estavam sendo submetidos, com altas jornadas de trabalho e baixos salários, dando origem ao sistema cooperativista.

Já no Brasil as bases do cooperativismo foram lançadas em 1610, mas somente dois séculos depois, em 1847, se têm registro do início do movimento cooperativista. O qual acabou evoluindo e conquistando um espaço próprio, definido por uma nova forma de pensar o homem. Por sua forma igualitária e social, o cooperativismo é aceito por todos os governos e reconhecido como fórmula democrática para a solução de problemas socioeconômicos (COOPEDER, 2007).

A agricultura brasileira, como afirma Gonçalves (2014), tem se dividido ao longo de sua história entre o suprimento da demanda por alimentos e o fornecimento de matéria prima para alguns ramos da indústria. Com o passar do tempo, e em meio a controversas opções políticas e econômicas, este setor foi se segmentando em algumas atividades, cujos extremos se consolidaram como agronegócio, de um lado, e pequena produção familiar, de outro. 
De acordo com Gonçalves e Souza (2005), a definição de propriedade familiar consta no inciso II do artigo $4^{\circ}$ do Estatuto da Terra, estabelecido pela Lei $\mathrm{n}^{\circ} 4.504$ de 30 de novembro de 1964, com a seguinte redação: “ propriedade familiar : o imóvel que, direta e pessoalmente explorado pelo agricultor e sua família, lhes absorva toda a força de trabalho, garantindo-lhes a subsistência e o progresso social e econômico, com área máxima fixada para cada região e tipo de exploração, e eventualmente trabalhado com a ajuda de terceiros" e na definição da área máxima, a lei $\mathrm{n}^{\text {o }} 8629$, de 25 de fevereiro de 1993, estabelece como pequena os imóveis rurais com até 4 módulos fiscais e, como média propriedade, aqueles entre 4 e 15 módulos fiscais.

Abramovay (1992) diferencia a agricultura familiar no interior das sociedades capitalistas mais desenvolvidas como uma forma completamente diferente do campesinato clássico. Enquanto que os camponeses podiam ser entendidos como "sociedades parciais com uma cultura parcial, integrados de modo incompleto a mercados imperfeitos", representando um modo de vida caracterizado pela personalização dos vínculos sociais e pela ausência de uma contabilidade nas operações produtivas. Já a agricultura familiar, segundo o mesmo autor, [...] é altamente integrada ao mercado, capaz de incorporar os principais avanços técnicos e de responder as políticas governamentais [...] Aquilo que era antes de tudo um modo de vida converteu-se numa profissão, numa forma de trabalho (ABRAMOVAY, 1992, p.22-127).

Atualmente, cerca de $85 \%$ do total de propriedades rurais do país pertencem a grupos familiares. De acordo com a Secretaria de Agricultura Familiar são 13,8 milhões de pessoas em cerca de 4,1 milhões de estabelecimentos familiares, o que corresponde a $77 \%$ da população ocupada na agricultura. (BRASIL, 2011)

A demanda por gêneros alimentícios no Brasil, atualmente dividida entre consumidores finais, empresas, restaurantes, instituições públicas e privadas, é caracterizada por uma grande variedade de produtos que vai dos frescos, como frutas, legumes e hortaliças, até os alimentos processados e prontos para o consumo, passando por uma gama enorme de laticínios, embutidos, grãos, carnes, entre tantos outros, cuja oferta pode ser caracterizada pela predominância de empresas ligadas ao agronegócio, cooperativas de pequenos e médios produtores, além de distribuidores de produtos importados.(GONÇALVES, 2014)

Cerca de $60 \%$ dos alimentos consumidos pela população brasileira e 37,8\% do Valor Bruto da Produção Agropecuária são produzidos por agricultores familiares. (BRASIL, 2011)

Segundo dados do Censo Agropecuário de 2006 (IBGE), o Estado de São Paulo possuía 151.015 estabelecimentos de agricultura familiar $(66,3 \%$ do total da 
agricultura) ocupando uma área de 2,5 milhões de hectares $(15,0 \%$ dos estabelecimentos). A agricultura familiar ocupava 328.177 trabalhadores ou $36,1 \%$ da mão de obra empregada na agricultura do estado.

A agricultura familiar no Estado de São Paulo apresenta características únicas e próprias de uma região extremamente dinâmica. De acordo com Belik e Rosa de Souza (2009), por ser um estado cuja base está amparada na economia industrial, em transição para uma sociedade de serviços, a agricultura em geral não é percebida entre a população pela sua importância. $O$ setor agropecuário representa não mais do que 1,6 $\%$ do PIB paulista e a mão de obra residente nas áreas rurais 5,7\% do total. Assim quem não está familiarizado com os indicadores do setor rural acaba não se dando conta do peso da agricultura familiar em São Paulo e da sua complexidade e heterogeneidade.

Estes produtores e seus familiares são responsáveis por inúmeros empregos no comércio e nos serviços prestados nas pequenas cidades. A melhoria de renda deste segmento por meio de sua maior inserção no mercado tem impacto importante no interior do país e por consequência nas grandes metrópoles.

Apesar dos números, a comercialização dos produtos oriundos da agricultura familiar sempre foi relatada como um desafio, dadas as dificuldades enfrentadas principalmente pelos pequenos produtores com relação ao acesso aos melhores canais de comercialização, colocando-os a mercê dos intermediários e atravessadores, que se apropriavam de boa parte da margem de comercialização de seus produtos. De forma a evitar essa situação e garantir maior segurança no mercado, uma considerável parcela da agricultura familiar tem investido em estratégias como o associativismo e o cooperativismo, com numerosos casos de sucesso pelo país. Além de ampliar o acesso desses agricultores aos diversos canais de comercialização existentes, o cooperativismo passou a incorporar ao longo dos anos estratégias para a diferenciação de produtos no mercado, como embalagens, marcas, processamento e comercialização direta dos mesmos, incorporando verticalmente atividades antes externas, a jusante das suas cadeias de suprimentos.

Enquanto nas grandes cooperativas tem se investido na profissionalização e especialização dos quadros técnico e administrativo, o que tem contribuído para o seu sucesso no mercado, nas pequenas associações e cooperativas issonão tem ocorrido. Gonçalves (2014) relata que a maior parte das cooperativas em atuação no estado de São Paulo mantém um quadro administrativo extremamente enxuto, composto geralmente por produtores e seus familiares no desempenho de cargos para os quais não houve preparação ou formação profissional. Apesar da importância atribuída aprofissionais como Agrônomos, 
Veterinários, técnicos agrícolas e administradores, para a melhoria dos aspectos técnicos e organizacionais das atividades desenvolvidas no campo e nas próprias associações e cooperativas, em nenhuma das 30 entidades estudadas pelo autor havia contratação de serviços destes profissionais. Todo o apoio técnico era demandado do poder público.

Nesta pesquisa analisou-se o caso daAssociação de Agricultores CEAVO Centro de Abastecimento de Votorantim-SP, que em 2002, mesmo sem apoio técnico e profissionalização de seu corpo administrativo,investiuem uma estratégia diferenciada de comercialização, ao criar um entreposto comercial próprio, para atender um público de feirantes, comerciantes e consumidores locais.

\section{MÉTODOS}

Para a realização desta pesquisa optouse por um estudo observacional, que compreendeu um conjunto de métodos de pesquisa composto por Revisão Bibliográfica e documental,focada na obtenção de informações acerca da agricultura familiar da região, visitas de campo e entrevistas estruturadas com os administradores da associação,onde buscou-se informações sobre seu histórico, estrutura administrativa e principais dificuldades encontradas em sua rotina operacional, que são descritas no tópico a seguir.

\section{RESULTADOS: A ESTRATÉGIA DA ASSOCIAÇÃO "CEAVO"}

Atualmente a região Administrativa de Sorocaba é caracterizada por uma mescla de um pequeno número de agricultores patronais e um razoável número de agricultores familiares. Segundo dados da CONABe do Ministério de Desenvolvimento Agrário, citadas por Gonçalves (2014), a região conta com cerca de 30 associações e cooperativas ligadas à agricultura familiar que reúnem um número estimado de 2000 agricultores, que abastecem tanto o mercado local, quanto outras regiões do estado.

Segundo o autor, a comercialização dos produtos da agricultura familiar da região tem se dado por canais diversificados, individualmente ou de forma associada, que incluem o uso de intermediários, a venda direta ao consumidor, venda direta a estabelecimentos comerciais, venda através de programas institucionais do poder público, e venda através de entrepostos de comercialização.

A unidade do CEAGESPde Sorocaba (Companhia de Entrepostos e Armazéns Gerais de São Paulo)é o principal entreposto da região, ecomercializa cerca de 10 mil toneladas de alimentos por mês, entre frutas, legumes, verduras e cereais, quase todos produzidos por pequenos e médios produtores da própria região, que têm como destino as feiras-livres, mercados, mercearias e restaurantes da região. 
No entanto, o uso de espaços formais como os stands do CEAGESP e as feiraslivres, ou mesmo a comercialização direta a estabelecimentos comerciais, representa custos que nem todos os agricultores familiares possuem condições financeiras de arcar individualmente, o que os coloca diante da alternativa dos atravessadores, um canal de comercialização arriscado e de ganhos reduzidos.

Foi nesse contexto que em 2002 foi criada a Associação "CEAVO" Centro de Abastecimento de Votorantim, com o objetivo de oferecer uma oportunidade para alguns agricultores familiares que não estavam conseguindo comercializar seus produtos na unidade regional do CEAGESP.

Segundo o presidente da Associação, a proposta surgiu de um pequeno grupo de agricultores que se reunia semanalmente em uma feira informal desde 1999 nas proximidades de onde hoje funciona $\mathrm{o}$ entreposto da associação, no município de Votorantim-SP (GONÇALVES, 2014).

$\mathrm{Na}$ época, o grupoprocurou apoio da administração municipal de Votorantim-SP paraque pudesse ocupar um lugar mais amplo, que acomodasse o número crescente de produtores e consumidores que se aglomeravam às margens da rodovia próxima ao local onde acontecia a feira. Com a falta de uma proposta melhor do poder público, o grupo optou por criar uma associação e alugar um terreno particular para a realização da feira, e desde então foi crescendo de forma desordenada e enfrentando inúmeros problemas.

Um desses problemas refere-se a estrutura local para a acomodação dos produtores e clientes. Diferente do que ocorre no CEAGESP, onde há docas para o descarregamento de caminhões, galpões amplos, stands em alvenaria, piso pavimentado, estacionamentos, banheiros, etc., o terreno alugado pela associação não possuía qualquer benfeitoria prévia.Como o plano inicial daquele grupo de agricultores se resumia em encontrar um local melhor do que as margens da rodovia, tal alternativa parecia ser suficiente.

No entanto, a falta de um planejamento inicial minimamente elaborado foi se revelando aos poucos importante, pois com o passar do tempo muitas demandas infra estruturais foram sendo reveladas, como a falta de banheiros adequados para os clientes e produtores, falta de cobertura para abrigar as pessoas nos dias chuvosos, falta de pavimentação nas vias de acesso e de espaço para o estacionamento dos veículos, e até mesmo de uma sede para que a associação pudesse atender novos ingressantes, realizar reuniões, guardar documentos, entre outras atividades.

Tais demandas levaram os associados a destinar parte de seu rendimento a construção dessas estruturas, como uma casa-sede com banheiros abertos ao público, cobertura para os stands, entre outras benfeitorias. No entanto, por se tratar de um local alugado, a 
opção por realizar as benfeitorias trouxe o risco de perde-las em uma possível mudança de local, fazendo com que a associação passasse a aceitar os constantes reajustes de aluguel imposto pelos proprietários, que tornou-se uma constante ameaça a sustentabilidade econômica dos negócios da associação.

Outra queixa constante dos administradores da associação era com relaçãoa falta de apoio das duas prefeituras, Sorocaba e Votorantim, que teriam responsabilidades sobre as vias de acesso ao local. Como se trata de um terreno localizado exatamente na divisa entre os dois municípios, a indefinição da responsabilidade sobre aspectos como pavimentação, saneamento e iluminação tornava necessária uma exaustiva negociação com ambas as prefeituras, inclusive com a interferência de políticos locais.

Entre as dificuldades enfrentadas durante estes doze anos de associação, destacam-se o baixo grau de instrução dos agricultores associadose a falta de apoio técnico e institucional, que acabaram retardando o desenvolvimento organizacional da entidade e dificultando o acesso a várias oportunidades. A dificuldade na preparação dedocumentos técnicos como planos e projetos, por exemplo, é relatada como um dos maiores problemas organizacionais da entidade, que tem resultado na perda de muitas oportunidadesjunto ao mercado, como na obtenção de linhas de crédito, e no acesso a políticas públicas.

Mesmo em meio a tantos desafios, a associação prosperou, e atualmente reúne 170 famílias agricultoras em 125 blocos de comercialização em seu centro de distribuição. Segundo o seu presidente, são comercializados, em média, mais de 900 mil $\mathrm{kg}$ de alimentos por mês. Cerca de $90 \%$ das vendas são realizadas por atacado, aos comerciantes da região, e os $10 \%$ restantes são comercializados no varejo, para as pessoas que visitam o local nos dias de feira, que ocorre três vezes por semana durante o ano todo. O Ceavo recebe produtores de 25 municípios e vende para famílias e comerciantes de 18 cidades.

\section{PROPOSTAS E CONSIDERAÇÕES FINAIS}

Este estudo analisou o caso da Associação de Agricultores CEAVO - Centro de Abastecimento de Votorantim-SP, que em 2002, mesmo sem apoio técnico e profissionalização de seu corpo administrativo, investiu em uma estratégia arriscada de comercialização, ao criar um entreposto comercial próprio, para atender um público de feirantes, comerciantes e consumidores locais.

Foi constatado que ao longo dos mais de 12 anos desde a fundação do entreposto, muitas dificuldades foram atravessadas, e vários desafios foram impostos aos associados que, carentes de um apoio mais incisivo do 
poder público local, arcaram com custos e prejuízos evitáveis.

A pesquisa apontou que assim como em outras situações descritas pela literatura, a falta de profissionalização do corpo técnico e administrativo da associação tem sido um dos principais entraves para o desenvolvimento dos negócios da entidade.

A dependência de um poder público paternalista, presente em vários momentos da história da agricultura familiar no Brasil pode, talvez, explicar a falta de iniciativa que acomete grande parte desse importante setor da economia brasileira.

No entanto, é imperativo que tais entidades invistam em profissionalização e em novas formas de gestão, pois não há espaço para amadores no mercado capitalista.A parceria com instituições privadas, consultorias, Universidades, empresas-junior, e mesmo serviços como os oferecidos pelo SEBRAE, podem oferecer um grande suporte às pequenas associações e cooperativas durante a fase de consolidação de seus negócios. No entanto, o apoio externo precisa ser visto como uma necessidade apenas temporária, que supra necessidades técnicas emergenciais enquanto essas competências ainda não estiverem plenamente desenvolvidas no interior de seus quadros técnicos e administrativos.

\section{REFERÊNCIAS}

\section{ABRAMOVAY, R. Paradigmas do}

capitalismo agrário em questão. São Paulo:

Hucitec, 1992.

BECHO, Renato Lopes. Elementos de

Direito Cooperativo. São Paulo: Dialética, 2002.

\section{BELIK, W E ROSA DE SOUZA, L}

RAlgumas Reflexões sobre os Programas de Alimentação Escolar na América Latina.

Planejamento e Políticas Públicas. São

Paulo, IPEA no. 33 jul/dez 2009, pp103-122.

BRASIL - Ministério da Agricultura, Pecuária e Abastecimento (MAPA). Programa de Aquisição de Alimentos (PAA). Brasilia, 2009. Disponível em: $<$ http://www.agricultura.gov.br>. Acesso em: 06 out. 2011.

\section{COOPEDER. O Surgimento do}

Cooperativismo No Mundo. Disponível em: $<$ http:// www.coopeder.org.br/conheca/cooperativism o/mundo.php_arquivos>. Acessado dia 28 nov. 2007

CREMONESE, Camila e

SCHALLENBERGER, Erneldo.

\section{Cooperativismo e Agricultura Familiar na}

Formação do Espaço Agrícola do Oeste do

Paraná. Disponível em: http://e- 
revista.unioeste.br/index.php/tempodaciencia/ article/viewFile/ 434/349>. Acessado dia 29 de nov. 2007.

GONÇALVES, Daniel Bertoli. Os desafios da agricultura familiar frente aos programas de compras públicas de alimentos: um estudo sobre agricultores da região sudoeste do estado de São Paulo. Revista da Universidade Vale do Rio Verde, v.12, n.1, Betim, MG. 2014. doi: http://dx. doi. org/10.5892/ruvrd. v12i1. 1413.

GONÇALVES, J. S.; SOUZA, S. A. M. Agricultura familiar: limites do conceito e evolução do crédito. Artigos: políticas públicas. Instituto de Economia Agrícola. Disponível em: <http://www.iea.sp.gov.br/out/verTexto.php?c odTexto=2521>. Acesso em 10 ago. 2005.

Agradecimentos: $\mathrm{O}$ autor agradece à FAPESP - Fundação de Amparo à Pesquisa do estado de São Paulo, pelo apoio institucional(processo n²014/21122-0) 